\title{
ComPlexUs
}

COMPLEX SYSTEMS METHODS

Complexus 2006;3:74-82 DOI: 10.1159/000094190

Published online: August 25, 2006

\section{Ambiguity in Art}

\section{Igor Yevin}

Mechanical Engineering Institute, Russian Academy of Sciences, Moscow, Russia

\section{Key Words}

Ambiguity $\cdot$ Multistable perception $\cdot$ Pattern recognition $\cdot$ Art $\cdot$ Criticality

\begin{abstract}
A non-linear theory proposed different models of perception of ambiguous patterns, describing different aspects of multistable behaviour of the brain. This paper aims to review the phenomenon of ambiguity in art and to show that the mathematical models of the perception of ambiguous patterns should be regarded as one of the basic models of artistic perception. The following type of ambiguity in art will be considered. Visual ambiguity in painting, semantic (meaning) ambiguity in literature (for instance, ambiguity which $\vee$. Shklovsky called 'the man who is out of his proper place'), ambiguity in puns, jokes and anecdotes, and mixed (visual and semantic) ambiguity in acting and sculpture. The complexity theory of the brain revealed that the human brain as a complex system operates close to the point of instability and ambiguity in art must be regarded as an important tool for supporting the brain near this critical point that gives human beings possibilities for better adaptation.
\end{abstract}

Copyright ( 2006 S. Karger AG, Basel

\section{Fax +4161306 1234 E-Mail karger@karger.ch www.karger.com}

KARGER (c) 2006 S. Karger AG, Basel 1424-8492/06/0033-0074 $\$ 23.50 / 0$

Accessible online at: www.karger.com/cpu
Igor Yevin

Mechanical Engineering Institute, Russian Academy of Sciences 4, Bardina, Moscow, 117324 (Russia)

Tel. +7 095576 0472, Fax +70951357769 E-Mail yevin@list.ru

\section{Simplexus}

Where science meets art there are those who see unsubtle reductionism as somehow detracting from aesthetics and there are those who suggest that art seeks objective reality only in a subjective way. The divide between art and science has seemingly never been greater, although some of our most revered historical intellects, perhaps most notably Leonardo da Vinci, would not have understood this arbitrary bifurcation of human endeavour. Indeed, the flip side of the cultural divide posits that art and science are simply two faces of the same coin, endlessly turning and laying the condition of reality bare through the machinations of the human mind.

In this paper, Yevin seeks to provide science with the tools necessary to understand the nature of artistic perception and so quantify our aesthetic sense. He reviews the notion of ambiguity in art and shows how a mathematical model of ambiguous patterns seen in artistic works can help us understand how the human brain functions. Moreover, ambiguity, whether an optical illusion or trompe-l'oeil in painting, a pun or joke, or the ambiguity we enjoy in both literature, drama, and even sculpture, he claims, could be intrinsic to the incredible adaptability of the brain. The human brain, after all, is considered to be the most complex system in the universe, its ability to process ambiguous patterns and sensory inputs may have evolved to allow it to function on the cusp of stability and so be amenable to adapting to any given environmental pressure with what we commonly refer to as creative thought.

One of the most famous, or infamous, of ambiguous artistic statements is the smile of Leonardo da Vinci's Mona Lisa, which is at once blissful and melancholic. The viewer's interpretation hinges on mood and preconceptions about the painting. Leonardo da Vinci was entirely deliberate in painting the model so that cues to her true mood in the mouth and eyes are hidden by the sfumato technique he employed. 

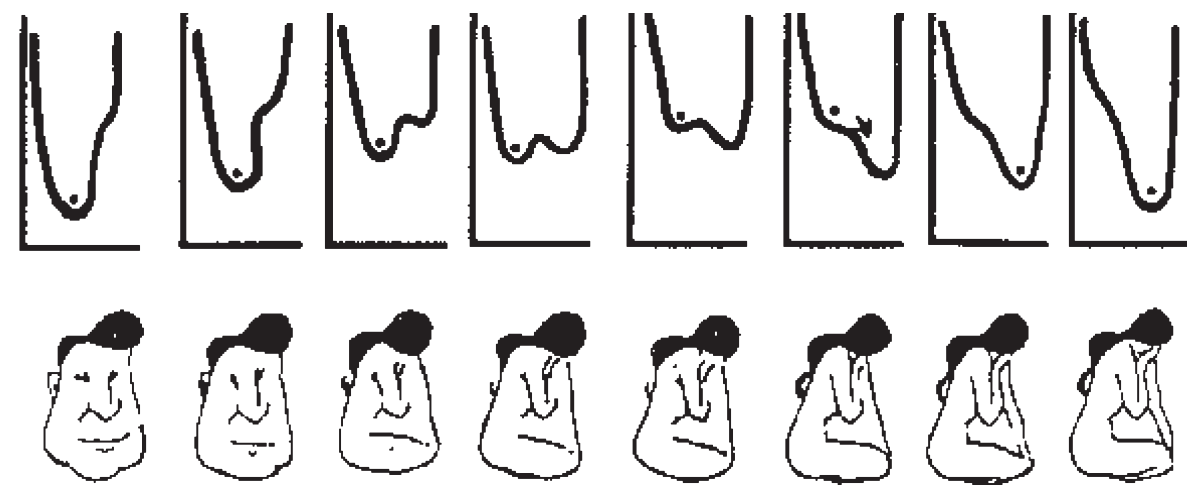

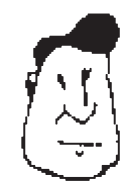

$\mathrm{R} 2$

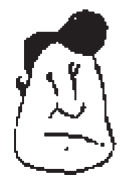

R3

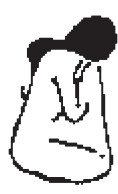

R4

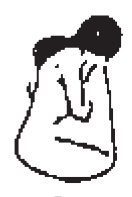

R5

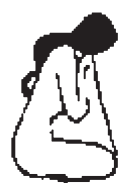

R6

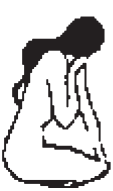

R7

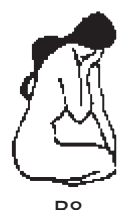

R8

Fig. 1. Ambiguous patterns are two-state systems. Their perception can be modelled by using an elementary catastrophe 'cusp'

\section{Non-Linear Models of Perception of Ambiguous Patterns}

In perception psychology, multistable perception of ambiguous figures is often considered as of a marginal curiosity. Nevertheless, this phenomenon is one of the most investigated ones in psychology. The first description of ambiguity was given by Necker in 1832. The best-known examples of ambiguous figures are specially designed patterns such Necker's cube or 'young girl-old lady'. But visual and semantic ambiguity is very often also connected with the fact that the available visual or semantic information is not sufficient by itself to provide the brain with its unique interpretation. The brain uses past experience, either its own or that of our ancestors, to help interpret insufficient and therefore ambiguous information.

Many patterns in our everyday life are, in a way, ambiguous patterns, but using additional information, we usually resolve or avoid ambiguity [1]. Legothetis [2] has recently shown that the resolution of ambiguity is an essential part of the job of consciousness .

This paper aims to review the phenomenon of ambiguity in art, to familiarize it with the present state and to show that the mathematical models of the perception of ambiguous patterns should be regarded as the basic models of artistic perception. Ambiguous patterns are examples of twostate,bimodal systems in psychology. When we perceive an ambiguous figure, like the fourth picture in the row in figure 1 , the perception switches between two interpretations, namely 'man's face' or 'kneeling girl' because it is impossible for the brain to recognize both interpretations simultaneously. Just like for any bifurcative state, it is impossible to predict in the case of an ambiguous figure which interpretation will appear first. G. Caglioti from the Milan Polytechnique Institute first paid attention to the fact that ambiguous figures are a cognitive analogue of critical states in physics.

Various authors pointed out that the perception of ambiguous figures has nonlinear properties, and that multistable perception could be modelled by catastrophe theory methods [3-5].

The switch between two interpretations could be described by elementary catastrophe 'cusp'

$$
x^{3}-b x-a=0
$$

where $a$ and $b$ are control parameters and $x$ is the state variable. The first parameter $a$ is called the normal factor and quantitatively describes the change in bias in the drawing in a 'shape space' from a man's face
Consequently, her enigmatic smile has inspired countless arguments in the half millennium since it was created.

Ambiguity, and in particular multi-stable perception of ambiguous figures, is textbook material for psychology undergraduates. Most people have seen the sketches described by Yevin in this paper and others: the old lady that reveals herself to be a young woman or the two opposing faces that are nothing more than a vase. And, of course, the Mona Lisa. Nevertheless, it is not entirely clear how visual and semantic ambiguity, which is so often connected to availability, or lack thereof, of information, preclude the brain from visualizing a unique interpretation. Recent research hints at the essential function of consciousness as to resolve ambiguities. When it fails in its task we are left with a feeling of discordance that can manifest itself as pleasure or pain, whether the ambiguity is in visual art, a dramatic line, or a joke.

When one looks at images such as the 'old lady, young woman' sketch, one feels an incredible sense of dissonance in that the revelation of old or young never occurs. Indeed, the mind seems to flip endlessly between bistable states, never settling on a single interpretation, and of course, wholly unable to see both states simultaneously. Such bistability is common throughout science and is the cognitive analogue of critical states in the physical sciences. For instance, ice water has a dual nature. It exists at a critical temperature and pressure and a disturbance in either can push the fluid to freeze solid or melt completely into liquid water. The ambiguous image similarly sits on such a catastrophic cusp, collapsing into one interpretation or the other depending on our mood and preconceptions at any given point in time. Yevin suggests that it should be possible to quantify the non-linear nature of our brain's response to such stimuli. Indeed, he describes a formula which superficially resembles a potential function borrowed 
to a woman's figure. Because this model may also be used for the description of the perception of situations with a double meaning, it is reasonable to develop the idea of 'shape space' or 'meaning space' first introduced by Osgood et al. [6].

The second parameter $b$ is called the splitting factor or bifurcation factor and describes how much detail is presented in the ambiguous figure.

The state variable $x$ is presented as a scale from +10 ('looks a lot like a man's face') to -10 ('looks a lot like kneeling girl'). For this model we could formally represent potential function

$$
V=\frac{1}{4} x^{4}+b \frac{1}{2} x^{2}+a x
$$

which is depicted in figure 1 , and consider a catastrophic jump from one image to another as non-equilibrium phase transition. It is worth noting that unlike in physical sciences, where the potential function is usually deduced from fundamental laws or standard theories, in mathematical models in psychology and other 'soft sciences' the potential function is hypothesized and is really considered as the potential energetic function, which should be minimized. In this case it might be also considered as the Lyapunov function in Hopfield's model of pattern recognition.

Actually, when viewing ambiguous figures, perception lapses into a sequence of alternations, switching every few seconds between two or more visual interpretations.

Haken $[7,8]$ offered an approach to the description of such oscillation in the recognition of ambiguous figures. Each pattern is described in this model as a vector in the space of quantitative parameters. There is a procedure for selecting noncorrelated parameters, which make it possible to reduce an information volume. The most informative parameters are the order parameters (all their peculiarities occur near critical points, as in the case of order parameters near phase transition $[7,8])$.

The pattern recognition procedure is the following. First, pattern prototypes are stored in the computer memory. Then, the pattern that should be recognized is inputted. The recognition dynamics is built in such a way that its vector evolves in a parameter space to the most similar pattern stored in the computer memory.

The prototype patterns are encoded by $V i_{\mathrm{i}}(i=1, \ldots, M)$. The components of every vector encode the features of the patterns. We can decompose each prototype pattern into its pixels and denote a pixel by its in$\operatorname{dex} j$. To each pixel we attribute a gray (or a colour) value $v j$. The set of all gray values $v_{j}$ forms a vector $V_{i_{\mathrm{i}}}\left(v_{1}, v_{2}, \ldots, v N\right)$. It is assumed that all these vectors are linearly independent.A pattern to be recognized is encoded by a vector $Q(0)$ and is inputted in a computer memory at $t=0$. A dynamic of pattern recognition is constructed so that the initial vector $Q(0)$ is pulled into one of prototype patterns $V k$ with which it mostly coincides.

A recognized pattern is presented as the linear combination of prototype patterns

$$
Q(t)=\sum_{j=1}^{M} d_{i}(t) V_{i}+\xi(t)
$$

where $d_{i}(t)$ is the order parameter, characterizing the degree to which a pattern is recognized, and $\xi(t)$ is a residual uncorrelated with $V i$ (it is proved that

$$
\lim |\xi(t)|=0)
$$

The dynamic of pattern recognition is described as a gradient process in networks with only $M$ neurons according to

$$
\begin{aligned}
& \dot{d}_{i}(t)=\lambda d_{i}-(B+C) d_{i} \sum_{j \neq i}^{M} d_{j}^{2}-C d_{i}^{3}, \\
& \lambda_{i}>0, B>0, C>0, d_{i}(0)=V_{i}^{\prime} Q(0)
\end{aligned}
$$

from physical science, but in terms of psychology is merely hypothesized and represents the brain 'flipping' between two states when confronted with ambiguity. The parameters of Yevin's formula provide a measure of the apparent physical differences between the two states in the ambiguous pattern. The formula can thus be employed in a computer pattern recognition system to define the old lady and the young girl, for instance, and so by analogy suggest ways in which the brain responds.

More sophisticated ambiguity in art is represented by the work of Giuseppe Arcimboldo who specialized in creating representations of human faces from inanimate objects. The Librarian for instance, at first glance, is obviously a person with a powdered wig and a heavy cloak. But, another look reveals 'him' to be nothing more than a pile of books, albeit arranged in an unconventional way so as to deceive. Fruit, leaves, twigs and other objects from the natural world are also Arcimboldo's building blocks for creating other ambiguous characters - 'gardener or vegetables in a bowl?', he asks us. Surrealist Salvador Dali too offered the world incredible ambiguities in his paintings and sculptures. The Mona Lisa and Jan Vermeer's Girl with a Pearl Earring, explains Yevin, represent the subtle palette of ambiguity, tugging at deep emotions and precluding 'closure'.

Novels and movie plots exploit ambiguities too. Commonplace examples of instability in a story for instance might be the spy operating undercover or a two-timing lover's secret wooing. At any moment, the agent may be unmasked, which provides for captivating suspense as our brains attempt to handle the ambiguity. Such ambiguity is represented widely in folk tales too, in which a cuckold secretes themselves into another's life - the wolf in Little Red Riding Hood - or a person is removed from his own domain into the unfamiliar world of another - The Prince and the Pauper, for instance. Even the ugly duckling and beauty and the beast-type stories 


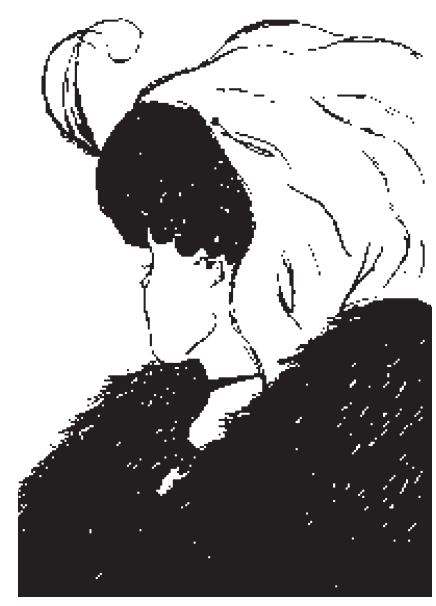

Fig. 2. Image ambiguity: 'young girlold lady'.

This system has only the attractors of the type $(0,0, \ldots, d k \neq 0, \ldots, 0)$. It can be shown that they must be either saddle points or nodes, but not limit circles (oscillations).

Ditzinger and Haken offered a synergetic model of the perception of ambiguous patterns, describing dynamical features of such perception (fig. 2). It is based on the model of pattern recognition described above and the model of saturation of attention. The recognition of ambiguous patterns is reduced to inputting only two pattern prototypes (e.g., 'young girl' and 'old lady') into a computer memory with the order parameters $d_{1}$ and $d_{2}$.In this case the dynamics of pattern recognition is described in the following way:

$$
\begin{aligned}
& \dot{d}_{1}=d_{1}\left(\lambda_{1}-A d_{1}^{2}-B d_{2}^{2}\right) \\
& \dot{d}_{2}=d_{2}\left(\lambda_{2}-B d_{1}^{2}-A d_{2}^{2}\right) \\
& \dot{\lambda}_{2}=g\left(1-\lambda_{2}-d_{2}^{2}\right) \\
& \dot{\lambda}_{1}=g\left(1-\lambda_{1}-d_{1}^{2}\right)
\end{aligned}
$$

where the overdot means $d / d t, \lambda_{1}$ and $\lambda_{2}$ are time dependent attention parameters, and $A, B$, and $g$ are constants. The last two equations describe the saturation of attention in the perception of prototype patterns. As the analysis shows, the oscillation of perception occurs when the appro-

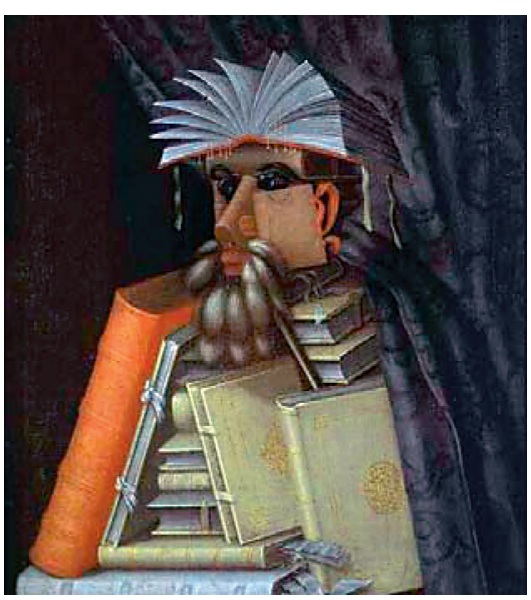

Fig. 3. The Librarian by Giuseppe Arcimboldo.

priate relations between constants are satisfied $[7,8]$. The recognition of ambiguous patterns has very profound and various analogies with numerous artistic phenomena. This perception model of visual ambiguous patterns could also be applied in the case of meaning ambiguity, because the perception of meaning also includes phenomena such as saturation of attention and the concept of the order parameter [9].

\section{Visual Ambiguity in Art}

Let us first consider the specially created visual ambiguity in art. The painting The Librarian by Giuseppe Arcimboldo is an example of such ambiguity in painting (fig. 3). At first sight we recognize a face, but a closer look reveals just an arrangement of different books.

The most famous example of ambiguity in painting is, of course, Mona Lisa by Leonardo da Vinci (fig. 4). In The Story of Art Gombrich [10, p. 228] said: 'Even in photographs of the picture we experience this strange effect, but in front of the original in the Paris Louvre it is almost uncanny. Sometimes she seems to mock at us, and then again we seem to catch something like sadness in her smile'. 'This is often contain plots in which ambiguity plays a critical role and is sustained until the story's climax.

Much of poetry too relies on hidden meaning, puns, homonyms and phononyms - all ambiguity. Ambiguity is also present in other art forms from sculpture to music in Cole Porter's 'strange change from major to minor', which alludes to the ambivalence of certain harmonies, which may resolve with either a happy or a sad tone depending on the composer's muse.

Yevin suggests one response of a brain confronted with ambiguity is laughter. The universal ha-ha-ha of people laughing is, he claims, a manifestation of the brain switching between two contrary states and recognizing the humour in ambiguity. Yevin does not say whether or not chimpanzees who use similar repeating staccato sounds in their communication are also experiencing a feeling of ambiguity, although a chimpanzee's 'laughter' is usually associated with physical contact such as tickling. However, tickling is in itself a highly ambiguous experience - both pleasurable and painful concomitantly.

Consider the ambiguity in this joke and imagine it is funny enough to make you laugh. Sherlock Holmes and Dr Watson have gone camping. They pitch their tent under the stars and go to sleep. Sometime in the middle of the night Holmes wakes Watson up. 'Watson,' he orders, 'look at the stars and give me your deduction'. Watson replies, 'I see millions of stars around any one of which might orbit a planet similar to Earth and therefore deduce we are not alone in the universe.' Holmes retorts: 'No, you idiot! Someone has stolen the tent!'

This 'joke' contains two different semantic interpretations of being able to see the night sky during a wakeful camping trip. Now, imagine it were a truly funny joke that made the shoulders judder and the ribs ache as the brain flips between the two possible interpretations. It is easy to see how Yevin's ha-ha-ha theory might well be valid. 


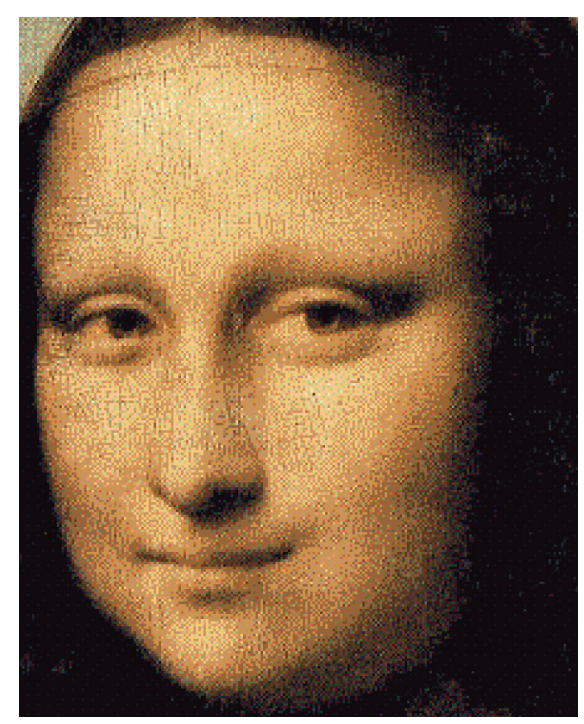

Fig. 4. The ambiguity of Mona Lisa's smile.

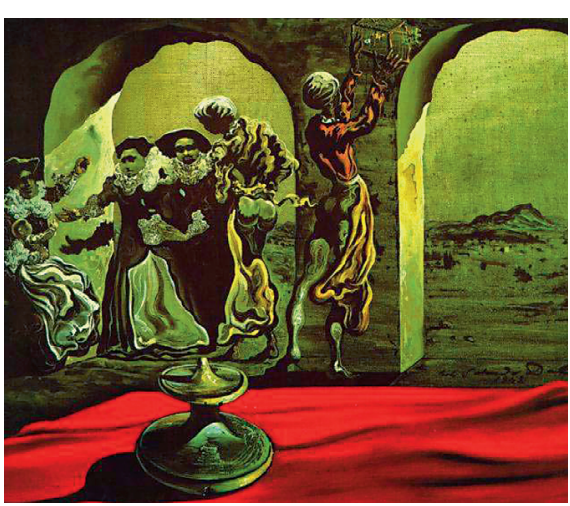

Fig. 5. The ambiguity of Voltaire's bust in Salvador Dali's painting Disappearing Bust of Voltaire.

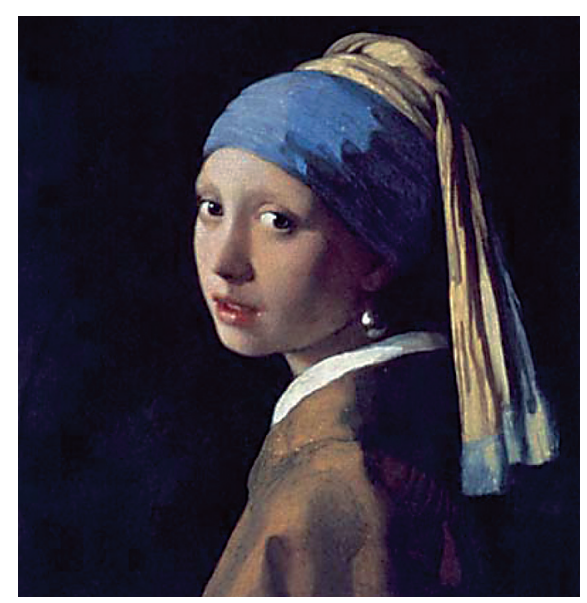

Fig. 6. Girl with a Pearl Earring by Jan Vermeer.
Leonardo's famous invention the Italians call "sfumato" - the blurred outline and mellowed colors that allow one form to merge with another and always leave something to our imagination. If we now turn to the "Mona Lisa", we may understand something of its mysterious effect. We see that Leonardo has used the means of his "sfumato" with the utmost deliberation. Everyone who has ever tried to draw or scribble a face knows that what we call its expression rests mainly in two features: the corners of the mouth, and the corners of the eyes. Now it is precisely these parts which Leonardo has left deliberately indistinct, but letting them merge into a soft shadow. That is why we are never quite certain in which mood Mona Lisa is really looking at us. Her expression always seems just elude us'.

The ambiguity of Mona Lisa's smile can be compared with ambiguous images like 'young girl-old lady'[11]. The oscillation in the perception of this painting can be described by Ditzinger-Haken's model.

The painting Disappearing Bust of Voltaire (fig. 5) by Salvador Dali is an example of another kind of visual ambiguity, when a human face is created with different figures.

\section{Semantic Ambiguity of Visual Scenes}

Let us consider the painting Girl with a Pearl Earring by J.Vermeer [12] (fig. 6). Many art historians consider this portrait a masterpiece of ambiguity, because it offers a wide range of interpretations. The face of the girl is at the same time somewhat sad and joyful, erotic and distant, submissive and yet dominant.

There is a humorous book called Captions Courageous by Reisner and Kapplow [13] attempting more or less witty reinterpretations of famous masterpieces of painting. This possibility to create new interpretations of famous paintings which are perceived as comic has to do with a lack of information [1] (fig. 7).
Yevin also explains that ambiguity need not rely on semantics to be funny. Comic impressionists mimic the voice and mannerisms of their victims and the comedy arises partly because we 'know' that we are watching the actor and yet we 'see' the person they impersonate. Again, the ha-ha-ha effect emerges as our brains flip from seeing the caricature to seeing the impressionist.

If much of humour resides in the bistable nature of a comic impressionist or two incongruous interpretations of a given situation as in Holmes and Watson sharing their (lack of) tent, then why do we not laugh at the Mona Lisa smile? Yevin suggests that the answer lies in the frequency at which our brains can oscillate between the two states. Recognizing the semantics that give rise to the humour of a punch line takes very little brain mass compared with the process of visualizing the Mona Lisa smile as blissful or melancholic. The visual cortex is an evolutionarily ancient brain structure and so is relatively slow compared with the much more recent language centres and their lightning responses. In these faster regions, bistable oscillation surely occurs at a higher frequency, which funnily enough coincides with the guttural response we know as laughter.

Is this perpetually elusive resolution the key to the human condition: the pleasure and pain of romantic love, the parent torn between clinging to a child or letting go, the humour in ambiguity, and ultimately the final bistable state that is life and death? Whatever the answer, such a reductionist view does not remove the pleasure of seeing the Mona Lisa smile nor stop us laughing at Holmes and Watson. Rather, it adds to our knowledge, provides new insights into human nature, and helps us appreciate the wonderfully complex system that is the human brain.

David Bradley of Sciencebase.com 


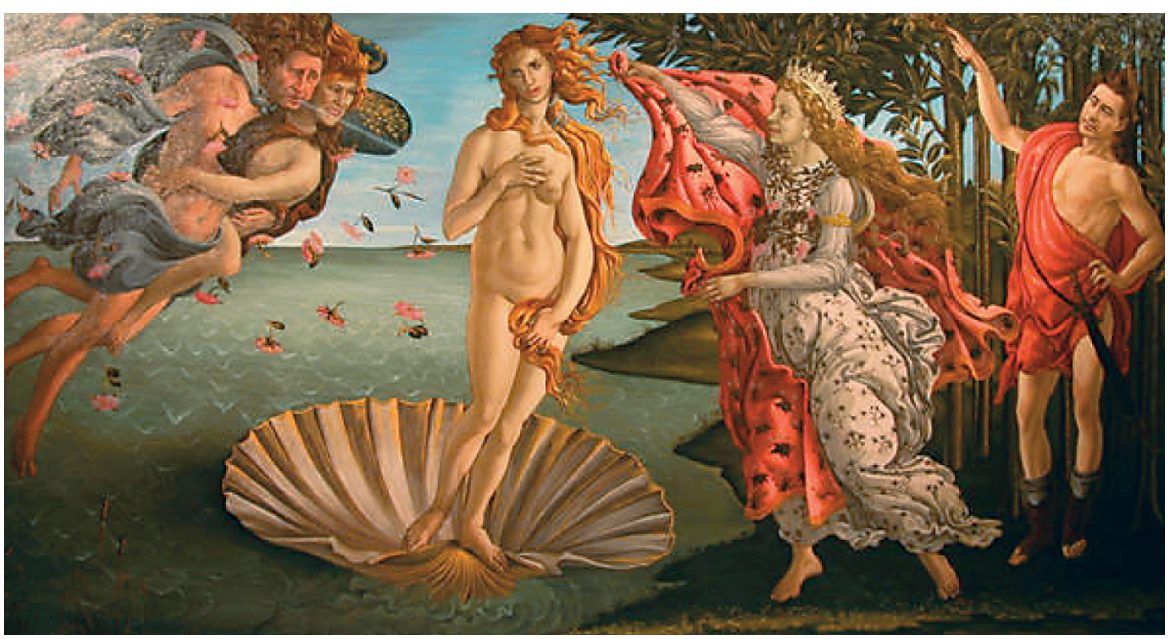

Fig. 7. Complex visual scenes usually allow different interpretations. This famous painting Birth of Venus by S. Botticelli may be headlined: 'Slip into this, it's a raid' (from the book Captions Courageous by Reisner and Kapplow [13]).

\section{Semantic Ambiguity in Plot Development and in Comic Situations}

A significant type of ambiguity in art involves the possible existence of two different states in an artwork (most often in the position of the main hero), one of them may be hidden for a certain time. A commonplace example of this form of instability exists in numerous book and movie plots in which a spy or Secret Service agent is hiding his identity while manoeuvring about in a hostile camp. At any moment, he may be unmasked, and it is the agent's task to extend his secret identity as long as possible.

In the well-known American movie RoboCop the main character is simultaneously a robot, incarnating a pitiless and perfect machine of revenge, and a human being, capable of deep and tender feelings.

Another, less banal example of an ambiguity of social nature - what Shklovsky [14] describes as 'the man who is out of his proper place' - is also widely present in art. According to Shklovsky [14], ‘.. The novels of olden times were based on the incidental falling out of a man from his society.
By almost fatal position of an illegal birth or a loss of documents has been motivated an introduction of a hero into the world which has been a destiny of millions. But a hero has been rescued from that world with the help of recovered documents. A hero of old novel is the one who is not in his proper place, a hero of one society finding himself in an absolutely different society. The History of Tom Jones, a Foundling by Henry Fielding, is an example of such a novel. The main character Khlestakov in the play by N. Gogol Inspector General obviously can also be described using this kind of ambiguity.

In Apuleius's Golden Ass the main character is, of course, out of his proper place because the ass in reality is a man. The plots of tales such as The Ugly Duckling by $\mathrm{H}$. Andersen and The Beauty and the Beast also have the same type of ambiguity, sustained over the entire period of the plot.

In the majority of the novels by Agatha Christie we deal with semantic ambiguity, as almost any character of these novels could turn out to be the murderer. This state of semantic ambiguity is skilfully maintained by the author until the out- come of the plot:'You know that I never deceive. I simply speak something such that it is possible to interpret double' - once Agatha Christie confessed.

Without the ambiguity of natural languages, the existence of poetry is impossible. According to Kolmogorov [15], entropy of language $H$ contains two terms: meaning capacity $h_{1}$ - the capability to transmit some meaning information in a text of appropriate length, and flexibility of language $h_{2}$ - a possibility to transmit the same meaning by different means. Namely $h_{2}$ is a source of poetic information, and the ambiguity of language is one of the causes of its flexibility. Languages of science usually have $h_{2}=0$, they exclude ambiguity, and cannot be used as a material for poetry. Rhythms, rhymes, lexical and stylistic norms of poetry will put some restrictions on a text. Measuring that part of the ability to carry information spent on those restrictions (denoted as $\beta$ ), Kolmogorov formulated the law according to which poetry is possible: if $\beta<h 2$. If the language has $\beta \geq h 2$, then poetry is impossible. We know that the brain resolves a visual ambiguity by means of oscillation. A semantic ambiguity (the ambiguity of meaning) is the result of ambiguous words or whole sentence. Semantic ambiguity, widely spread in comic situations, also resolves by oscillations.

The ambiguity of humour is often a clash of different meanings. It involves double or multiple meanings, sounds, or gestures, which are taken in the wrong way, or in incongruous ways.

Here is D.D. Minayev's epigram: 'I am a new Byron' - you proclaim. I can agree with you: The British poet was lame The rhymes of yours are also lame.

The method used in this epigram involves a comparison based on different distant meanings (Byron was lame, and a 
vain poet was also lame, but in his rhymes). The situation described in this epigram is common to a lot of semantically ambiguous comic situations, which contain two states. One state we could call a state with high social status. This position is honourable and sometimes brings profit. The second state we could call a state with low social status. Everybody avoids occupying it. In the aforesaid example, the state with the high social status ('a good poet') we connect with the words 'a new Byron'. Another poet is trying to achieve this state. But the author of the epigram unexpectedly transfers the poet to the second state with a low social status. This state we associate with the words 'the rhymes of yours are also lame'. Such an unexpected leap is achieved by using the same word ('lame') for totally different states.

So, the comic is very often linked to the sudden transition from a state of high social status to a state of low social status, or the other way round. Is it a single transition? Does it happen only once? Of course, not. It is a multistable perception of meaning. The rhythmical, repeating nature of laughter (ha, ha, ha, etc.) shows that such transitions are repeated. Evidently, a laughing person mentally oscillates every time from the state of high social status to the state of low social status and vice versa, by comparing them. As a result, the rhythmical laughter is generated by the nervous system.

Let us also consider the following anecdote about Sherlock Holmes and Dr. Watson. Sherlock Holmes and Dr. Watson go camping. They pitch their tent under the stars and go to sleep. Sometimes in the middle of the night Holmes wakes Watson up. 'Watson, look up at the stars, and tell me what you deduce.'Watson says, 'I see millions of stars, and if there are million of stars, and if even a few of those have planets, it's quite likely there are some planets like Earth, and if there are a few planets like Earth out there, there might also be life.' Holmes replied: 'Watson, you idiot, somebody stole our tent.'

We see that Watson and Holmes offered two different semantic interpretations of the same visual picture of a starry sky and while Watson gave one possible interpretation of seeing a starry sky, Holmes paid attention to the semantic context and linked it to where they were sleeping.

The origin of the oscillatory character of laughter should be connected with the fundamental property of the distributed neuron set, i.e. as the oscillation occurring in the perception of ambiguous patterns. According to Ditzinger-Haken's model of recognizing ambiguous patterns, stable limit cycles can be formed in systems of usual non-linear differential equations for those variables which describe the visual perception (e.g. attention). Evidently, this is the common characteristic of distributing neuron sets. This is why it is manifested not only in evolutionary low stages (the ancient visual-morphologic structure of nervous and psychological activity of a human being), but also in its latest stages (in the semantic analytical structures of the left cerebral hemisphere).

Comic situations are very often associated with polysemantic, i.e. semantically ambiguous, situations. Another situation of perception of ambiguous patterns occurs in the parody of a famous person by an actor. On one hand, we can recognize the manners, gestures, style and voice of that famous person. On the other hand, we see quite a different person. The same method is used in literary and poetic parodies. Every time we deal with a bimodal situation with a double meaning. As a result, we have the oscillation of perception, and laughter is one of the external manifestations of this oscillation.

It can be assumed that in ambiguous comic situations oscillations occur between two semantic images. The phenomena of synchronization are typical for a self-organizing process in an active medium (and the nerve substance is an active medium). From that, we can conclude that the period of oscillation between semantic patterns coincides with the period of outward macroscopic oscillations, manifested as laughter with the duration of about $0.1 \mathrm{~s}$. This value is much smaller than the oscillation period, which occurs when recognizing ambiguous figures (1-5s).

Why does laughter occur when the perception is made that situations have double meanings, and not when there is visual perception of ambiguous patterns? We can explain this by essentially different periods of the corresponding oscillations. In the visual perception this period is approximately equal to $t=10 \mathrm{~s}$, and in the perception of the ambiguity of meaning this period is about $t=0.1 \mathrm{~s}$. This difference could be explained by the fact that a much smaller mass of nerve substance is involved in creating semantic patterns compared with constructing visual patterns. This is because visual information is processed in the massive and ancient visual cortex, and semantic patterns are interpreted in the compact Broke-Vernike zone in the left brain hemisphere. Anecdotes, jokes and sketches are deliberately created as short as possible (laconic), in order to reduce the time needed for the saturation of attention in the process of recognition.

\section{Mixed Ambiguity}

Ambiguity of Sculpture

We have looked at visual ambiguity in painting [see also 12] and semantic ambiguity in jokes, anecdotes and puns. Let us consider mixed (visual and semantic) ambiguity, taking an example from the art of sculpture. Sculpturing involves an ability to depict representatives of a living nature (most often humans and animals) with materials of an inanimate nature (wood, stone, bronze).

In the creativity of different sculptors a prevalence of one of these phases with respect to another can be observed. In Michelangelo's works we can see the triumph of life and even the spiritual under the inert 
matter of stone. Gombrich [10] wrote in The Story of Art: 'While in The Creation of Adam Michelangelo had depicted the moment when life entered the beautiful body of a vigorous youth, he, now, in the Dying Slave, chose the moment when life was just fading, and the body was giving way to the laws of dead matter. There is unspeakable beauty in this last moment of final relaxation and release from the struggle of life - this gesture of lassitude and resignation. It is difficult to think of this work as being statue of cold and lifeless stone...'.

It is interesting to note that the ambiguity of the art of sculpture influences literature, because the plots of some works of arts in literature are based on the idea of an animated statue, that is, the transition of 'inanimate-animate' (such as the opera Don Giovanni by Mozart, Copper Horseman, Stone Guest by A. Pushkin and, of course, in the ancient legend about the sculptor Pygmalion).

\section{Ambiguity of Dolls}

In the essay Dolls in the System of Culture Y. Lotman [16] describes as ambiguous (as in sculptures) the nature of this cultural phenomenon closely linked to the ancient opposition of alive and dead, and spiritual and mechanical. At the same time, in contrast to a sculpture, the doll does not invite contemplation but play. It serves as a certain stimulator provoking creativity.

\section{Ambiguity of Acting}

Like any human being, an actor has in his everyday life a certain set of rather stable physiological and psychological personal characteristics: sex, appearance, timbre of voice, gait, and temper. Acting involves the ability to create a second phase, a 'role' phase, different from the original physiological and psychological nature of the actor. In other words, a bimodal 'actor-role' state created may be compared with ambiguous patterns, for instance, the pattern where we see in turn the 'young girl' or the 'old lady'. One could say that in this case the young girl 'plays the role' of the old lady and vice versa.

In acting, the existence of two polar types of actors can be observed: (1) The actor as a bright, brilliant personality, an eccentric person of original appearance (Alain Delon, Arnold Schwarzenegger). It is rather easy to make a parody of such actors. (2) The actor with outstanding abilities for transformation and reincarnation (Laurence Olivier, Alec Guiness). In this case, it is very difficult to make a parody.

Y.Lotman [16, p. 658] noted that in the cinema more than in the theatre the spectator does not only see the role, but also the actor. Observing the playing of a famous actor we alternately focus our attention on the guise (image) of the actor familiar to us from other movies and on characteristics of the role which the actor plays. Such an oscillation of attention is the reason why with reference to acting we use the word 'play'.

In the case of acting the prototypes are, for instance, Laurence Olivier (the image of the actor) and Othello (the image of the character). Therefore, according to the common law of perception of ambiguous patterns, an oscillation of our attention takes place, and we see in turn either the actor or his role.

Just as the bimodal nature of the art of sculpture gives rise to plots about an animated statue, the bimodality of acting makes it possible to use a phase transition called 'character invasion' for plot development [17].

The main hero of the film A Double Life plays the role of Othello for such a long time that it begins to affect to him psychologically, making him more and more jealous of his beloved, and like the stage character, he strangles her and then kills himself. In the film Jesus of Montreal the actor playing the role of Jesus Christ becomes transformed into a Christlike figure [17].
As a rule, all bimodal metastable states at the end of the movies turn into stable, one-modal states as a result of bifurcation.

\section{Conclusion}

In ordinary speech, and especially in scientific communication, in general we try to avoid ambiguity. In contrast, in humour, it is one of the aims to create ambiguous situations to provoke laughing. And in art as a whole ambiguity is an indispensable, necessary part.

'....art is supposed to have multiple meanings. It is self-defeating to increase one aspect of meaning. The more a single meaning dominates a work, the less it is a work of art. Something that has one and only one meaning - no matter how interesting or important that meaning is - is no longer a work of art' [18, p. 46].

Understanding the ambiguous nature of art makes it possible to formulate the problem of computer simulation of artistic creativity as computer production of ambiguous images and meanings (for instance, by means of genetic algorithms) [19].

Synergetics and the theory of complexity revealed that the human brain operates close to an unstable point, because only close to criticality could the human brain create new forms of behaviour. Ambiguity in art is an important tool for keeping the brain close to this unstable, critical point. 


\section{References}

1 Kruse P, Stadler M: Ambiguity in Mind and Nature: Multistable Cognitive Phenomena. Berlin, Springer, 1995.

2 Legothetis NL: Vision: A window on consciousness. Sci Am 1999; 11: 69-75.

-3 Poston T, Stewart I: Nonlinear model of multistable perception. Behav Sci 1978; 23:318-334.

4 Stewart IN, Peregoy PL: Catastrophe theory modeling in psychology. Psychol Bull 1983; 94: 336-362.

-5 Ta’eed LK, Ta’eed 0, Wright JE: Determinants involved in the perception of Necker cube: an application of catastrophe theory. Behav Sci 1988; 33: 97-115.

6 Osgood C, Suci G, Tannenbaum P: The Measurement of Meaning. Urbana, University of Illinois Press, 1957.

7 Haken H: Principles of Brain Functioning. Berlin, Springer, 1996.

8 Ditzinger T, Haken H: Oscillations in the Perception of the Ambiguous Patterns. Biol Cybern 1989;61: 279-287.

9 Wildgen W: Ambiguity in linguistic meaning in relation to perceptual multistability; in Kruse P, Stadler M (eds): Ambiguity in Mind and Nature. Berlin, Springer, 1995.

10 Gombrich E: The Story of Art. New York, Phaidon, 1995.

11 Caglioti G: Dynamics of Ambiguity. Berlin, Springer, 1992.

12 Zeki S: Inner Vision. Oxford, Oxford University Press, 1999.

13 Reisner B, Kapplow H: Captions Courageous. New York, Abeland-Schuman, 1954.

14 Shklovsky VB: Tetiva (in Russian): Moscow, Iskusstvo, 1967.

15 Kolmogorov AN: Theory of Poetry (in Russian). Moscow, Nauka, 1968, pp 145-167.

16 Lotman Yu: About Art (in Russian). St. Petersburg, Iskusstvo, 1998.

17 Neuringer C, Willis R: The cognitive psychodynamics of acting: character invasion and director influence. Empir Stud Arts 1995; 13/1: 47-54.

18 Martindale C: The Clockwork Muse. New York, Basic Books, 1990.

19 Yevin I: Phase transition as a fundamental model of creativity. Proceedings of International Conference on Informatics and Control. St. Petersburg, 1997, pp 502-505. 